\title{
A Dimensão Estratégica das Redes Horizontais de PMEs: Teorizaçõese Evidências
}

\author{
Alsones Balestrin \\ Lilia Maria Vargas
}

\section{Resumo}

No presente artigo é feita uma reflexão sobre o tema redes interorganizacionais, envolvendo aspectos teóricos e conceituais das tipologias de redes interorganizacionais e de redes horizontais de pequenas e médias empresas (PMEs), conduzindo o debate para uma tese central: a configuração em rede como recurso estratégico para a competitividade das PMEs. Na seqüência do artigo, são apresentados os aspectos metodológicos e os resultados de um estudo de caso realizado em uma rede horizontal de cooperação formada por 44 PMEs da indústria de confecções, localizada na Região Sul do Brasil. As evidências teóricas e empíricas sinalizam que a configuração em rede permite às PMEs alcançarem os seguintes benefícios: maiores trocas de informações e conhecimentos entre as empresas, participação e vendas de produtos em feiras, lobbying, melhorias nos processos empresariais, participação de palestras e de cursos de formação, barganha de preço junto aos fornecedores, marketing conjunto, acesso a novos representantes, maiores garantias no fornecimento de crédito aos clientes, maior facilidade de comercialização de insumos entre as empresas e ganhos de economias de escala, de escopo e de especialização.

Palavras-chaves: redes; cooperação; pequenas e médias empresas; estratégia.

\begin{abstract}
The present article reflects upon the interorganizational networks topic, dealing with theoretical and conceptual aspects of the typologies of interorganizational networks and horizontal networks of small and medium organizations (SMOs), leading the debate to the central thesis: the network configuration as a strategic resource for competitiveness of the SMOs. Next, the methodological aspects are presented, as well as the results of a case study developed with a horizontal network of cooperation comprised by 44 SMOs of the clothing industry, located in the South Region of Brazil. Theoretical and empirical evidences indicate that the network configuration allows the SMOs to achieve benefits such as: greater information and knowledge exchange between companies, participation and sales of products in expositions, lobbying, improvement of enterprise processes, participation in conferences and training courses, price bargaining with suppliers, joint marketing, access to new representatives, greater guarantees in providing credit to customers, facilitated sales of inputs between companies, and gains in economies of scale, scope and specialization.
\end{abstract}

Key words: networks; cooperation; small and medium organizations; strategies. 


\section{INTRODUÇÃo}

A reconhecida importância no campo organizacional e social tem demandado crescente interesse nas pesquisas sobre o fenômeno das redes interorganizacionais nas mais variadas áreas do conhecimento, como a economia, a sociologia, a ciência política e a administração. A idéia subjacente aos interesses de estudo é de que a configuração em rede promove ambiente favorável ao compartilhamento de informações, de conhecimentos, de habilidades e de recursos essenciais para os processos de inovação. A configuração em rede consiste, então, em forma eficaz para as empresas alcançarem competitividade nos mercados por meio de complexo ordenamento de relacionamentos, em que as firmas estabelecem interrelações.

O interesse por tal temática vem sendo motivado pela reflexão de alguns autores estrangeiros, como Perrow (1992) e Human e Provan (1997), que associaram a tipologia das redes de cooperação ao desempenho das pequenas e médias empresas (PMEs), ou pelos trabalhos desenvolvidos por autores brasileiros, como Casarotto e Pires (1999), ao estudarem o comportamento das PMEs do Norte da Itália, e Amato Neto (2000), ao apresentar exemplos de redes interorganizacionais nos países da América do Sul. A revisão analítica da literatura sobre essa temática permitiu a compreensão da relevância estratégica das redes em ambientes competitivos, sobretudo por facilitar a sinergia de esforços entre PMEs na direção de objetivos comuns. No presente artigo, serão aprofundadas algumas teorizações sobre as redes horizontais de cooperação, apresentando-se como objetivo central a identificação de evidências teóricas e empíricas sobre a possibilidade delas servirem como recurso estratégico para melhorar o desempenho competitivo das PMEs.

Para alcançar o objetivo proposto, o artigo está estruturado da seguinte forma: (1) reflexão sobre o tema redes interorganizacionais, abordando-se algumas definições conceituais e as principais correntes teóricas utilizadas no seu estudo; (2) apresentação das diferentes tipologias de redes, encaminhando-se o debate para as características específicas das redes de PMEs; (3) desenvolvimento de algumas teorizações sobre a temática central, ou seja, os aspectos estratégicos das redes horizontais para a competitividade das PMEs; (4) síntese da metodologia utilizada na pesquisa e na análise dos principais resultados de um estudo de caso realizado em uma rede horizontal de cooperação, formada por 44 PMEs da indústria de confecções, localizada na Região Sul do Brasil; e (5) considerações relativas às implicações e limitações do estudo. 


\section{REDES INTERORGANIZACIONAIS}

O termo rede não é novo e apresenta diversos significados e aplicações nos mais variados contextos, há algum tempo. Originalmente, ele se reportava a uma pequena armadilha para capturar pássaros, formada por um conjunto de linhas entrelaçadas, cujos nós eram formados pelas intersecções das linhas (Marcon e Moinet, 2000). No século XIX, esse termo adquiriu sentido mais abstrato, denominando todo o conjunto de pontos com mútua comunicação. Autores como Fombrun (1997) e Castells (1999) definem rede como um conjunto de nós interconectados, possibilitando que esse conceito amplo seja utilizado em diversas áreas do conhecimento. No campo de estudos das ciências sociais, o termo rede designa um conjunto de pessoas ou organizações interligadas direta ou indiretamente (Marcon e Moinet, 2000).

Para Castells (1999) a intensidade e a freqüência da interação dos atores sociais são maiores se esses atores forem nós de uma rede do que se não pertencerem à ela. Observa-se que as redes intensificam a interação, promovendo redução espaciotemporal nas inter-relações dos seus atores, como fatores altamente estratégicos para a competitividade das organizações do século XXI (Fayard, 2000).

No campo organizacional, a noção de rede é aplicada a uma ampla variedade de formas de relações entre firmas, como, por exemplo, no caso de joint ventures, alianças estratégicas, relações de terceirização e subcontratação, distritos industriais, consórcios, redes sociais, redes de cooperação entre pequenas e médias empresas, entre outras (Powell, 1987; Oliver, 1990; Grandori e Soda, 1995). Isso ocorre pelo fato de a noção de rede ser suficientemente abstrata. Para Fombrun (1997) o conceito de rede tem sido empregado para caracterizar um conjunto de fluxos, por exemplo, recursos e informações, entre um conjunto de nós, por exemplo, indivíduos, grupos, organizações e sistemas de informações.

O amplo escopo conceitual do termo rede proporcionou seu interesse por crescente número de pesquisadores na área de ciências sociais. Segundo levantamento realizado por Oliver e Ebers (1998) no período de 1980 a 1996, em quatro das principais publicações sobre estudos organizacionais, havia um total de 158 artigos que tratavam explicitamente sobre o tema redes interorganizacionais. As publicações estavam assim distribuídas: American Sociological Review (26 artigos), Administrative Science Quarterly (55 artigos), Academy of Management Journal (34 artigos) e Organizations Studies (43 artigos). Esses dados indicam a crescente preocupação com uma melhor compreensão do fenômeno de redes, tanto no campo organizacional quanto no campo social.

Para Nohria e Eccles (1992) existem três razões principais para o aumento do 
interesse no tema sobre redes nos estudos organizacionais: (1) a emergência da nova competição, como a que está ocorrendo nos distritos industriais italianos e do Vale do Silício. Se o velho modelo de organização era a grande firma hierárquica, o modelo da organização considerada característica da nova competição é a rede de inter-relações laterais intra e interfirmas; (2) o surgimento das tecnologias de informação e de comunicação (TICs) tornaram possível uma maior capacidade de inter-relações de firmas dispersas; e (3) a consolidação da análise de redes como disciplina acadêmica, não restrita somente a alguns grupos de sociólogos, mas expandida para ampla interdisciplinaridade dos estudos organizacionais.

Observa-se que o reconhecimento do ponto de vista teórico ocorre pelo fato de as redes poderem ser, e na verdade são, estudadas a partir de diferentes abordagens teóricas. Os estudos sobre redes oferecem preciosa base de interesses comuns e um potencial diálogo entre os vários ramos da ciência social. Isso se torna evidente a partir dos estudos de Caglio (1998) e Oliver e Ebers (1998), ao identificarem que as investigações sobre redes interorganizacionais foram conduzidas com base nas seguintes correntes teóricas: (1) economia industrial - identificou diferentes classes de custos de produção, como economias de escala, de escopo, de especialização e de experiência, como variáveis explicativas da eficiência das redes (Teece, 1980; Eccles, 1981; Turati, 1990); (2) estratégias interorganizacionais - destacaram a configuração em rede como fator estratégico para o alcance e a manutenção de vantagens competitivas (Jarillo, 1988; Fayard, 2000; Marcon e Moinet, 2000); (3) dependência de recursos - salientou que um dos fortes condicionantes na formação das redes interorganizacionais é a necessidade da empresa de buscar recursos complementares, sejam eles tangíveis (tecnologia, matéria-prima etc.) ou intangíveis (informação, conhecimento, habilidades etc.) (Pfeffer e Salancik, 1978); (4) redes sociais (social networks) - evidenciaram que a posição dos atores em uma rede influencia a organização de seus membros e apresenta forte influência nas interrelações junto à rede (Burt, 1992; Powell, 1996); (5) custos de transação consideraram as redes como ótimas formas para reduzir a incerteza, o risco e a ineficiência nas transações da empresa com seu ambiente econômico, reduzindo, assim, seus custos nas transações econômicas (Powell, 1987; Jarillo, 1988); (6) teoria institucional - constatou que as organizações buscam ganhar legitimidade junto ao seu ambiente institucional no momento de se estruturarem em rede (Dimaggio e Powell, 1983; Grabher, 1993); e (7) teorias críticas e radicais questionaram o argumento da eficiência na formação das redes e destacaram que estas são formadas por representarem poderosos instrumentos na formação de elites e classes dominantes, bem como o exercício do poder e da dominação (Perucci e Potter, 1989; Salancik, 1995).

É importante salientar que, mesmo não sendo uma unanimidade no campo científico, essas diversidades teóricas e paradigmáticas não devem ser vistas 
como excludentes, e sim como complementares para o estudo das redes. Oliver e Ebers (1998) assinalam a necessidade de utilizar múltiplas lentes teóricas e paradigmáticas com o objetivo de fazer uma leitura mais completa da complexidade das redes. Esse debate sugere a reflexão da necessidade de o pesquisador libertar-se da vinculação a uma única maneira de enfocar a realidade, buscando utilizar, em suas pesquisas, teorias e metodologias complementares em amplas formas de triangulação.

\section{Tipologias de Redes Interorganizacionais}

A diversidade de tipologias de redes interorganizacionais provocou certa ambigüidade no próprio entendimento do termo. Essa questão foi objeto da análise de Castells (1999), com base no argumento de que as redes interorganizacionais aparecem sob diferentes formas, em diferentes contextos e a partir de expressões culturais diversas. Exemplo disso são as redes familiares nas sociedades chinesas; as redes de empresários oriundos de ricas fontes tecnológicas dos meios de inovação, como no Vale do Silício; as redes hierárquicas comunais do tipo keiretsu japonês; as redes organizacionais de unidades empresariais descentralizadas de antigas empresas verticalmente integradas e forçadas a se adaptarem às realidades atuais; as redes horizontais de cooperação, como as existentes no norte da Itália, e as redes internacionais resultantes de alianças estratégicas entre grandes empresas que operam em diversos países.

Na tentativa de oferecer melhor compreensão da diversidade de tipologias de redes interorganizacionais, Marcon e Moinet (2000) criaram um gráfico denominado mapa de orientação conceitual, indicando, a partir de quatro quadrantes, as principais dimensões sobre as quais as redes são estruturadas (vide Figura 1).

\section{Figura 1: Mapa de Orientação Conceitual}

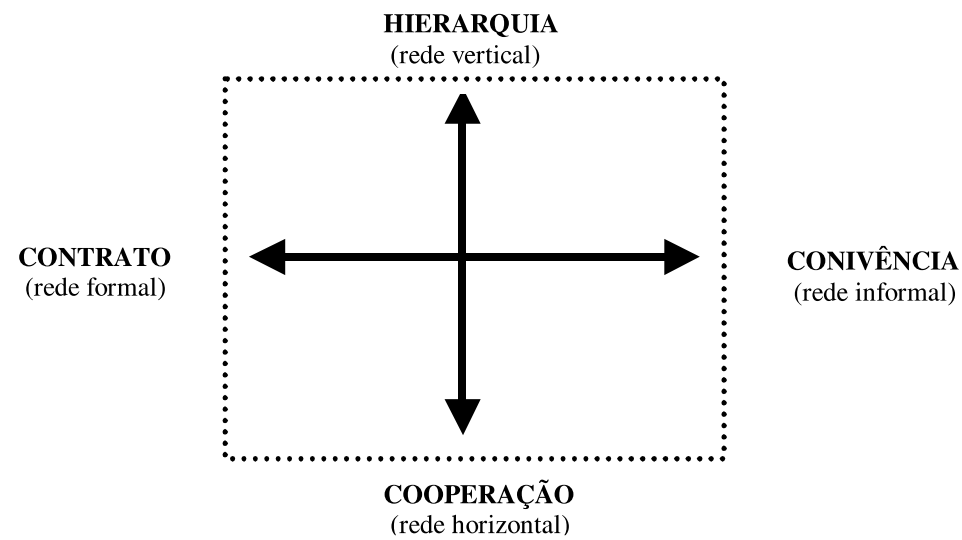

Fonte: adaptado pelos autores do modelo de Marcon e Moinet (2000). 
Segundo as orientações desse mapa conceitual, pode-se observar que o eixo vertical se relaciona com a natureza dos elos gerenciais estabelecidos entre os atores da rede. Tais elos podem representar uma atividade de cooperação, no caso de uma rede horizontal, como as redes de cooperação entre PMEs; ou grau de ligação hierárquico, no caso de uma rede vertical, como uma rede do tipo matriz/filial. Já o eixo horizontal representa o grau de formalização estabelecido nas relações entre os atores. Esse grau pode mover-se de uma conveniência informal entre os atores, no caso de relações de amizade, afinidade e parentesco, tais como ocorrem nas associações, nos clubes, nas redes de amigos, até relações formalmente estabelecidas por contratos entre as partes, no caso de contratos jurídicos, como ocorre na formação de joint-ventures.

Deve-se destacar que, em cada um dos diversos pontos do quadrante, poderá ser encontrado um tipo particular de configuração de rede, elucidando, assim, a ampla diversidade de tipologias de redes interorganizacionais existentes. Logo, de acordo com as orientações do mapa conceitual (vide Figura 1) e com as evidências de outros estudos, as redes podem ser amplamente classificadas, como se explica a seguir.

- Redes verticais: a dimensão da hierarquia. Certas redes têm clara estrutura hierárquica. Segundo Marcon e Moinet (2000), essa configuração é utilizada, por exemplo, pelas grandes redes de distribuição que adotam a estratégia de redes verticais para estarem mais próximas do cliente, como as grandes redes de distribuição integradas, distribuição alimentar e bancos. Em geral, essas relações são semelhantes às estabelecidas entre matriz/filial, em que as filiais possuem pouca autonomia jurídica e administrativa. A essa dimensão hierárquica subjaz a noção de empresa em rede, com a qual são designadas as empresas cuja organização adota a configuração de rede em razão da dispersão espacial.

. Redes horizontais: a dimensão da cooperação. As redes de cooperação interfirmas são constituídas por empresas que guardam cada uma sua independência, mas que optam por coordenar certas atividades específicas de forma conjunta, com os seguintes objetivos: criação de novos mercados, suporte de custos e riscos em pesquisas e desenvolvimento de novos produtos, gestão da informação e de tecnologias, definição de marcas de qualidade, defesa de interesses, ações de marketing, entre outros. Essas redes constituem-se sob a dimensão da cooperação de seus membros, que escolhem a formalização flexível para melhor adaptar a natureza de suas relações. Nesse modelo de cooperação interorganizacional, existe grande heterogeneidade de formas, como os consórcios de compra, as associações profissionais, as redes de lobbying e as alianças tecnológicas (Marcon e Moinet, 2000). Em termos de estratégia em 
rede, as relações interfirmas formam ambiente de aprendizagem por meio da cooperação. Essas relações são complexas, junto às quais os atores concorrentes escolhem cooperar dentro de certo domínio. Assim, as redes favorecem a concentração de esforços, sem privar a liberdade de ação estratégica de seus membros.

. Redes formais: a dimensão contratual. Knorringa e Meyer-Stamer (1999) defendem que algumas redes são formalizadas por meio de termos contratuais, que estabelecem regras de conduta entre os atores. Redes como as alianças estratégicas, os consórcios de exportação, as joint-ventures e as franquias são exemplos de redes fortemente formalizadas.

. Redes informais: a dimensão da conivência. As redes de conivência permitem os encontros informais entre os atores econômicos (empresas, organizações profissionais, instituições, universidades, associações etc.), portadores de preocupações semelhantes. Esses encontros permitem a troca de experiência e de informação sobre as bases da livre participação. As redes de conivência também permitem criar uma cultura de cooperação e de auxílio ao estabelecimento de relações interempresariais mais freqüentes e estruturadas (Marcon e Moinet, 2000). Nessa dimensão, as redes são formadas sem qualquer tipo de contrato formal que estabeleça regras; elas agem em conformidade com os interesses mútuos de cooperação, baseados, sobretudo, na confiança entre os atores.

De acordo com as teorizações apresentadas, observa-se que dificilmente existirão duas redes estruturadas de maneira idêntica. Assim, o esforço de tentar abranger todas as possibilidades de redes interorganizacionais em algumas dezenas de tipologias pré-definidas, não deixa de ser uma simplificação forçada da ampla diversidade de tipologias de redes.

Mesmo com essa múltipla diversidade, conforme observado no modelo apresentado por Marcon e Moinet (2000), o que fica evidente na análise da literatura, nesse campo de estudo específico, é o fato de que a grande maioria das pesquisas, principalmente aquelas realizadas por autores anglo-saxões, privilegiou arranjos como joint-ventures e alianças estratégicas entre grandes empresas. Outras configurações não menos importantes, como as redes horizontais de PMEs, tiveram pouco espaço para reflexão nos estudos sobre redes interorganizacionais.

\section{Redes de Pequenase Médias Empresas}

São várias as justificativas apresentadas para o estudo das PMEs, sendo que Souza (1995) destaca as seguintes: (1) estímulo à livre iniciativa e à capacidade 
empreendedora; (2) relações capital/trabalho mais harmoniosas; (3) possível contribuição para a geração de novos empregos e absorção de mão-de-obra, seja pelo crescimento de PMEs já existentes, seja pelo surgimento de novas; (4) efeito amortecedor dos impactos do desemprego; (5) efeito amortecedor das flutuações na atividade econômica; (6) manutenção de certo nível de atividade econômica em determinadas regiões; (7) contribuição para a descentralização da atividade econômica, em especial na função de complementação das grandes empresas; e (8) potencial de assimilação, adaptação, introdução e, algumas vezes, geração de novas tecnologias de produto e de processo.

No entanto, inseridas em ambiente hipercompetitivo, as PMEs, na maioria das vezes, apresentam certas dificuldades, tais como obter melhores preços e vantagens na compra de matérias primas e componentes, custos de participação em feiras, custos de campanhas publicitárias, custos de reciclagem e treinamento da mão-de-obra, atualização tecnológica, acesso a linhas de crédito e financiamento, custos de aluguel, custos envolvidos na exportação de produtos etc. Esses problemas dificilmente desaparecerão; contudo podem ter seus efeitos neutralizados ou amenizados pela ação coletiva das PMEs.

A partir da consciência da necessidade de atuação conjunta e de cooperação entre PMEs, almejando tornarem-se eficientes e competitivas, surge a lógica da configuração em rede. No entanto, mesmo com a reconhecida capacidade de eficiência coletiva pela ação em rede, poucos autores dedicaram-se ao estudo da configuração de redes de PMEs. Human e Provan (1997) destacam a existência de apenas alguns estudos isolados, como é o caso do elaborado por Inzerilli (1990), que usou a perspectiva de custos de transação para descrever como uma base de confiança em um contexto social facilita o sucesso das PMEs do norte da Itália. Lorenzoni e Ornati (1988) e Brusco e Righi (1989) e confirmaram a importância de fatores ambientais para o crescimento de PMEs por meio de redes. Em seu trabalho, Saxenian (1994) descreveu a emergência de uma infraestrutura nos Estados Unidos para apoiar o estilo europeu de sistemas cooperativos.

Para Perrow (1992) o fenômeno das redes de PMEs tem sido pouco estudado tanto pelas teorias clássicas quanto pelas teorias marxistas. Entretanto a forma de produção representada pela grande firma integrada, defendida originalmente por Chandler, tornou-se um modelo declinante em face das necessidades contemporâneas de flexibilização. O problema da teoria de Chandler foi negligenciar completamente o papel atribuído à confiança e à cooperação nos modelos econômicos (Perrow, 1992). Já as teorias marxistas lançam forte crítica ao modelo capitalista, sendo o foco maior de preocupação a exploração dos trabalhadores nas firmas; porém tais teorias pouco falam sobre o tamanho da 
firma, as redes interfirmas, o redesenho da produção, as associações de negócios, a competição, a eficiência e a infra-estrutura que tornam as redes viáveis. Segundo Perrow (1992), as teorias clássicas e marxistas precisam ser questionadas, pois ambas negligenciaram o poder econômico de três fatores que ajudam a explicar o sucesso das redes de PMEs: as economias de escala por meio de redes, a confiança e a cooperação que coexistem com a competição e o estado de bemestar social causado pelo aumento da eficiência coletiva de setores industriais regionais.

A dimensão da confiança e da cooperação possivelmente representa papel central no sucesso alcançado pelas redes de PMEs, o qual dificilmente será alcançado por outras formas de redes entre grandes empresas e muito menos pelas grandes empresas integradas. Tal fato foi evidenciado por Sabel (1991), que destaca que a confiança nunca poderá ser intencionalmente criada, e sim gerada a partir de uma estrutura ou de um contexto adequados. Diante dessa evidência, Perrow (1992) argumenta que, embora a confiança não possa ser criada, ela poderá ser encorajada por uma estrutura ou por um contexto criados deliberadamente.

Desse modo, existem algumas características no contexto das redes de PMEs que formam ambiente profícuo na geração de confiança entre as firmas; por exemplo: (1) as firmas compartilham e discutem informação sobre mercados, tecnologias e lucratividade; (2) existe suficiente similaridade entre processo e técnicas das firmas e, assim, cada uma poderá entender e julgar o comportamento das outras; (3) as relações são estabelecidas a longo prazo; (4) existe pouca diferença entre tamanho, poder ou posição estratégica das firmas; (5) ocorre periódica rotação de lideranças para representar o conjunto de firmas; (6) ocorre similar recompensa financeira para as firmas e empregados dentro delas; e (7) há alcance de vantagem econômica pela experiência coletiva das firmas, pelo aumento das vendas e pelos ganhos marginais. A possibilidade da confiança aumenta onde existem essas condições, sendo que as redes de PMEs maximizam a possibilidade de tais condições em relação ao modelo da firma integrada.

Para melhor entendimento das especificidades das redes de PMEs, faz-se necessária uma distinção entre outros arranjos, como joint-ventures e alianças estratégicas. Nesse sentido, Human e Provan (1997) salientam que as redes de PMEs diferem das joint-ventures e de outras formas de alianças estratégicas entre grandes empresas em razão de três dimensões principais:

. as redes de PMEs são geralmente criadas para fornecer um fórum direto de atividades e relações entre os seus membros, que permanecem independentes, mesmo trabalhando em atividades conjuntas. Os atores dessas redes perseguem 
objetivos comuns por meio de interações coordenadas de dez, vinte ou mais firmas individuais, enquanto as joint-ventures são geralmente formadas por duas grandes empresas.

. as redes de PMEs promovem complexas e recíprocas interdependências, em que os seus membros fornecem inputs e recebem outputs uns dos outros. Essas inter-relações são usualmente coordenadas pelas próprias firmas da rede, e os mecanismos de coordenação são geralmente pouco formais e facilitados pela própria dinâmica de interação dos membros. Já nas joint-ventures, a coordenação é exercida por meio de contratos formais.

- o critério de participação em uma rede de PMEs enfatiza a proximidade geográfica pela qual as firmas-membros combinam competências centrais para o alcance de objetivos organizacionais comuns que não alcançariam de forma individual. Já para as joint-ventures, não existe a necessidade de proximidade geográfica.

Outro fator relacionado à configuração de redes de PMEs foi apresentado por Perrow (1992), destacando que essas tipologias de redes geralmente se inserem em ambiente institucional que é essencial para sua sobrevivência e para sua economia, o qual abrange incentivos de governos locais e regionais, serviços educacionais, associações comerciais que fornecem informação econômica, treinamento e serviços de marketing. Esse ambiente, comumente encontrado nos distritos industriais italianos, apresenta forte contribuição para o desenvolvimento de regiões e para o próprio progresso das PMEs.

Convém salientar que existem várias tipologias de redes de PMEs que poderiam estar localizadas em diversos pontos do mapa conceitual apresentado Marcon e Moinet (2000), conforme a Figura 1. Algumas já foram profundamente estudadas, como é o caso das redes verticais de subcontratação, em que as PMEs fornecem serviços e produtos para outras empresas. No entanto as reflexões apresentadas neste item dizem respeito às redes horizontais de cooperação, em que as PMEs se unem, com a finalidade de somar esforços para o alcance de determinados objetivos comuns.

Segundo as evidências compiladas a partir da revisão do campo de estudos, uma rede horizontal de PMEs apresenta as seguintes características: (1) é formada por um grupo de PMEs; (2) as PMEs situam-se geograficamente próximas; (3) as PMEs operam em segmento específico de mercado; (4) as relações entre as PMEs são horizontais e cooperativas, prevalecendo mútua confiança; (5) a rede é formada por indeterminado período de tempo; e (6) a coordenação da rede é exercida a partir de mínimos instrumentos contratuais que garantam regras básicas de governança. 


\section{Configuração em Rede como Estratégia de Competitividade para as PMES}

Em uma perspectiva estratégica, pode-se considerar a configuração em rede como meio para alcançar um fim. Desse modo, ao participar de uma rede, a empresa busca alcançar certos objetivos que dificilmente seriam alcançados de forma individualizada. Nesse sentido, Marcon e Moinet (2000) apresentam alguns atributos que fazem das redes a configuração organizacional adequada para determinados objetivos organizacionais estratégicos.

- Fluidez. Significa a capacidade de flexibilidade e adaptabilidade das redes. As redes adaptam-se melhor às novas dimensões do ambiente. Essa propriedade fundamental permite-lhes efetuar quatro tipos de inter-relações: (1) no espaço, a rede permite colocar em relação subconjuntos ou unidades geograficamente dispersas; (2) no tempo, a rede assegura a permanência das ligações entre atores; (3) do ponto de vista social, a rede permite colocar em relação atores em condições diferentes, sem implicar a mudança dessa condição; e (4) do ponto de vista organizacional, a rede pode tornar-se alternativa à forma rígida de organização.

. Finalidade. É a razão de ser da rede, seja política, religiosa, filosófica, científica, econômica, cultural e/ou social. Essa finalidade encontra-se por vezes incorporada nos membros da rede e orienta, habitualmente, as escolhas éticas, em que a rede evolui e inspira seus projetos.

- Capacidade de realizar economias relacionais. A rede reduz a dispersão de esforços e permite ganho de tempo. A interconexão dos atores significa agilidade.

. Capacidade de aprendizagem. A aprendizagem não é exclusividade das redes, mas as condições de aprendizagem no contexto específico das redes são particulares. A aprendizagem coletiva apresenta a lógica do ciclo de aprendizagem, ou seja, cada um evolui em função do outro.

Esses atributos das redes, como flexibilidade e adaptabilidade, podem ser considerados como valiosos em face da atual dinâmica da economia mundial. Ebers e Jarillo (1998) destacam que, por meio de redes interorganizacionais, uma empresa poderá alcançar e sustentar vantagem competitiva a partir das seguintes origens: (1) aprendizado mútuo, que levará a empresa a suportar melhor o desenvolvimento de produtos; (2) coespecialidade, em que as firmas participantes se tornam lucrativas em novos nichos de produtos e mercados; (3) melhor fluxo de informação, facilitando a coordenação do fluxo de recursos 
entre as empresas e reduzindo a incerteza nas relações, uma das principais fontes de custos de transação; e (4) economias de escala, resultado de investimentos conjuntos, como, por exemplo, em P\&D.

No universo das PMEs, a estratégia em rede poderá representar meio eficaz para o desempenho competitivo, porquanto, organizadas em redes, essas empresas somam esforços para competir com as grandes. A partir de pesquisas realizadas junto a redes de PMEs, Human e Provan (1997) identificaram quatro grupos de principais finalidades estratégicas alcançadas pelas empresas, em seguida explicitados.

- Trocas interfirmas. Referem-se às transações diretas entre as firmas da rede. As principais inter-relações foram de negócios (compra e venda de produtos entre as empresas da rede); de informação (informações tecnológicas, de mercado, de produtos, de soluções de problemas); de amizade (existência de ambiente de trabalho amistoso e de confiança entre os membros da rede); e de competências (existência de ambiente de compartilhamento de melhores práticas entre os atores).

- Credibilidade organizacional. Diz respeito ao ganho de legitimidade externa pelo fato de as empresas estarem associadas à rede.

- Acesso a recursos. Refere-se ao papel das redes no sentido de facilitar para seus membros o acesso a novos mercados, tecnologias e suprimentos.

. Desempenho financeiro. Algumas firmas descreveram os benefícios econômicos que alcançaram, em curto espaço de tempo, após se organizarem em rede.

Como se pode observar, as motivações estratégicas que levam à formação das redes interorganizacionais podem ser amplas e variadas. No entanto uma fundamentação econômica que merece destaque é o fato de as configurações em rede terem demonstrado eficiente forma de governança e coordenação das relações econômicas (Powell, 1987). Tradicionalmente, duas outras formas institucionais de governança foram distinguidas com freqüência nas redes: o mercado e a hierarquia.

Williamson (1979), a partir de Coase (1937), foi quem definiu o mercado e a hierarquia como os dois modos alternativos de organização da atividade econômica. Ele considera que uma firma contempla diferentes curvas de custos na produção de cada um dos subcomponentes que constituem o produto final. Caso existam algumas firmas no mercado produzindo o mesmo bem, a priori a mais eficiente forma de organizar a produção consistirá em uma firma 
especializada na produção de cada um dos subcomponentes do produto. Assim, a firma especializada apresentará curva decrescente de custos e fornecerá a outras firmas, que terão menor custo em relação à produção desses componentes por meio da sua integração vertical. Porém o que se pode observar é que o comportamento das organizações geralmente não ocorre dessa maneira.

A explicação para tal fato, segundo Williamson (1979), é que nas relações econômicas interfirmas existem custos de transação que tornam mais caro o subcomponente em relação à produção pela própria firma. Esses custos são originados pelas ineficientes transações de determinada organização com o seu mercado, ocorrendo sobretudo pelas seguintes razões: racionalidade limitada do tomador de decisões, incerteza sobre o futuro e possibilidade de comportamento oportunista por parte de determinados atores econômicos. Logo, a falta de confiança nas relações da empresa com o seu ambiente e a possibilidade de comportamento oportunista por parte de alguns agentes representam questões centrais na geração dos custos de transação. Segundo a presente reflexão, na ausência de custos de transação, as firmas não integrariam suas funções. Contudo, se existem custos de transação, as firmas integram as atividades que poderiam ser feitas por subcontratados.

Jarillo (1988), em seu clássico artigo, afirma que existe uma questão que não foi discutida por Williamson (1979), a saber: os custos de transação podem ser afetados pela ação consciente de um empresário, sendo esta uma das principais fundamentações econômicas para a estratégia em rede. A confiança nas interrelações dos atores é um dos fatores que promove a redução dos custos de transação e torna a existência das redes economicamente viáveis (Jarillo, 1988). Em atmosfera de confiança, os problemas são resolvidos com maior eficiência, porque a informação e o know-how são trocados mais livremente (Boss, 1978).

Outra sustentação estratégica da viabilidade econômica das redes é quanto à problemática da inovação, entendida, segundo a concepção de Schumpeter, como ruptura do equilíbrio estacionário e abrangendo modificações nas empresas, tais como: (1) introdução de novo bem ou de nova qualidade de certo bem; (2) introdução de novo método de produção; (3) abertura de novo mercado para uma indústria; (4) nova fonte de matéria prima ou produto semi-acabado; (5) estabelecimento de uma nova organização em determinada indústria (Napoleoni, 1963).

Esse processo de inovação e transferência de conhecimento não é um processo simples e unidirecional, que ocorre em determinado tempo. Pelo contrário, segundo Mowery e Rosenberg (1989), é um processo complexo e interativo, pois o fluxo de informações ocorre em duas vias e é concebido como atividade 
contínua de pesquisa, formada e estruturada pelas forças econômicas, pelo conhecimento tecnológico e pela demanda dos consumidores por diferentes categorias de produtos e serviços.

Para Rothwell (1995), nos últimos 40 anos, a percepção do modelo de inovação dominante e, por extensão, as práticas inovadoras têm passado por algumas mudanças, que podem ser identificadas por diferentes gerações do processo inovador. Segundo o autor, atualmente o processo inovador passa a ser um sistema integrado e em rede. A inovação é uma ação conjunta e cooperada de diversos atores internos e externos da organização, como empresas, fornecedores, clientes, além de outras instituições de caráter público ou privado. Assim, a colaboração no seio de uma rede poderá facilitar a reunião de complementaridade de habilidades de diferentes firmas (Richardson, 1972). Em geral, as tecnologias demandam o uso simultâneo de diferentes conjuntos de habilidades e bases de conhecimentos em um processo de inovação, o que poderia estar limitado a uma empresa individual (Powell, Koput e Smith-Doerr, 1996). Outro efeito das relações diretas colaborativas emergem das economias de escala, sobretudo no caso de grandes projetos de pesquisas.

Portanto a estrutura em rede funciona como canal de comunicação, em que cada firma conectada poderá tanto receber quanto transmitir informação (Rogers e Kincaid, 1981). O papel das redes interfirmas como mecanismo difusor de informação e facilitador de compartilhamento de conhecimento pode ser significativo no contexto tecnológico (Powell, Koput e Smith-Doerr, 1996), pois a inovação é freqüentemente uma atividade intensiva em informação e conhecimento externo à empresa. As interconexões dos atores podem ser relações contratuais - parceria de P\&D e joint-ventures - ou informais - envolvendo a participação em uma comunidade técnica. Ambos os ambientes são propícios para a transferência de conhecimentos necessários aos processos de inovação (Powell, 1998).

A partir dessas evidências teóricas, é possível constatar que a configuração em rede poderá facilitar o alcance de objetivos estratégicos que dificilmente seriam alcançados, caso essas empresas trabalhassem de modo individual. No entanto, mesmo com a existência dessas evidências, pode-se observar que o valor estratégico das redes para as organizações foi pouco explorado. Tal fato pode apresentar duas justificativas: a primeira refere-se ao recente surgimento do tema redes nos estudos organizacionais; a segunda, e a mais provável, refere-se ao fato de que a perspectiva de redes interorganizacionais colide frontalmente com alguns postulados clássicos utilizados pela corrente dominante no campo de estratégia, arraigados no comportamento de competição. Um exemplo a ser citado, bastante utilizado nos textos sobre estratégia, é o princípio da exclusão competitiva 
de Gause: segundo esse professor da universidade de Moscou, considerado o pai da biologia matemática, duas espécies que conseguem seu sustento de maneira idêntica não podem coexistir (Henderson, 1998). Entretanto deve-se salientar que, diferentemente das variadas espécies de bactérias em competição por sustento, as organizações poderão coexistir em um mesmo ambiente, cooperando racionalmente, a fim de alcançarem objetivos comuns. Este é o princípio que nutre o desenvolvimento das redes.

Ao apresentar a fundamentação teórica, buscou-se melhor compreender as redes horizontais e sua contribuição para o desenvolvimento das PMEs. Na seqüência do artigo, serão apresentados os aspectos metodológicos e os resultados de um estudo de caso que está sendo conduzido, inicialmente, em rede de PMEs da Região Sul do Brasil, buscando evidências empíricas à tese central do debate.

\section{Metodologia da Pesquisa}

A presente pesquisa usou como método o estudo de caso. O caso selecionado para ser analisado foi a rede AGIVEST (Associação Gaúcha de Indústrias do Vestuário), formada por 44 pequenas indústrias do vestuário, localizadas na Região Sul do Brasil. A AGIVEST faz parte do projeto Redes de Cooperação do Governo do Estado do Rio Grande do Sul e foi constituída em setembro de 2001 com os seguintes objetivos: ampliação de mercado, melhorias tecnológicas e alcance de maior competitividade para as pequenas empresas associadas, conforme dados fornecidos pela rede AGIVEST, em agosto de 2002. A escolha da rede AGIVEST como objeto de estudo deveu-se às seguintes motivações: (1) é uma rede de PMEs, formada há um ano e que já apresenta resultados alcançados; (2) é uma rede de PMEs industriais que busca a inovação em seus produtos, para melhor competir em mercados nacionais, o que pode ser comprovado pelo lançamento de uma coleção de produtos em uma Feira Nacional; e (3) pelo interesse da Secretaria de Desenvolvimento e Assuntos Internacionais (SEDAI) do Governo do Estado do Rio Grande do Sul em estudar tal rede, ensejando contatos do pesquisador com o consultor, o presidente e os empresários da rede.

A operacionalização da pesquisa decorreu da sistematização dos construtos teóricos e das variáveis a serem observadas no estudo de campo, conforme o Quadro 1. 


\section{Quadro 1: Operacionalização dos Construtos Teóricos e Variáveis Observadas}

\begin{tabular}{|c|l|}
\hline Construtos teóricos & \multicolumn{1}{|c|}{ Variáveis observadas na pesquisa de campo } \\
\hline $\begin{array}{c}\text { Aprendizagem } \\
\text { coletiva }\end{array}$ & $\begin{array}{l}\text { Aprendizagem coletiva pela interação dos atores e partilha de informações, } \\
\text { habilidades, competências, conhecimento sobre soluções de problemas etc. }\end{array}$ \\
\hline $\begin{array}{c}\text { Economias de escala } \\
\text { Poder de barganha }\end{array}$ & Eçonomias de escala por meio da ação coletiva das PMEs. \\
\hline $\begin{array}{c}\text { Ampliação de } \\
\text { mercado }\end{array}$ & Acesso a novos mercados, clientes e representantes. \\
\hline $\begin{array}{c}\text { Economias de escopo } \\
\text { e de especialização }\end{array}$ & $\begin{array}{l}\text { Aumento do portofólio de produtos da rede, ao mesmo tempo que as PMEs } \\
\text { ganham economias de especialização. }\end{array}$ \\
\hline $\begin{array}{c}\text { Redução dos custos de } \\
\text { transação }\end{array}$ & $\begin{array}{l}\text { Redução dos custos de transação pelo aumento de confiança entre os atores, } \\
\text { reduzindo a incerteza e o comportamento oportunístico nas inter-relações. }\end{array}$ \\
\hline $\begin{array}{c}\text { Facilitação do } \\
\text { processo de inovação }\end{array}$ & $\begin{array}{l}\text { Inovação nos produtos, nos métodos de produção e na estrutura } \\
\text { organizacional. }\end{array}$ \\
\hline
\end{tabular}

As evidências empíricas foram coletadas a partir de sete entrevistas, realizadas com os seguintes atores: cinco entrevistas com dirigentes de PMEs da rede AGIVEST, escolhidos de forma aleatória; uma entrevista com o consultor da rede AGIVEST e uma entrevista com o presidente da rede. Cada entrevista teve duração de aproximadamente 60 minutos e foi realizada pelo próprio pesquisador. O pesquisador utilizou um roteiro de entrevista, elaborado com base nas variáveis de pesquisa constantes no Quadro 1, com o objetivo de apresentar uma seqüência lógica nos questionamentos aos entrevistados. As entrevistas foram gravadas e, posteriormente, submetidas a uma análise de conteúdo. Com o intuito de melhor entender a dinâmica de coordenação e do processo decisório da rede, o pesquisador utilizou, como meio complementar, a técnica de observação participante em uma assembléia da rede AGIVEST.

\section{Resultados do Estudo de Caso}

Sensibilizado com o papel de fortalecer o desenvolvimento local e regional e estimulado pelo desempenho dos sistemas locais de produção em nível mundial, o Governo do Estado do Rio Grande do Sul lançou em dezembro de 2000 o projeto Redes de Cooperação, cujo objetivo visou à promoçao e ao fortalecimento da cooperação entre PMEs. Dois anos após o seu lançamento, já foram constituídas 33 redes de PMEs nos mais diversos segmentos econômicos, abrangendo 733 
empresas e um total de 5.000 empregados. O projeto conta com a participação de seis universidades, que disponibilizam 42 consultores que prestam auxílio à formação e à gestão da rede. Existem também outras ações que fortalecem e viabilizam o desenvolvimento das redes, como o acesso facilitado ao crédito, o desenvolvimento de um programa de capacitação gerencial e o atendimento de demandas específicas das redes, como, por exemplo, o incentivo à participação em feiras e eventos, conforme dados divulgados pela SEDAI em 2002.

Foi possível observar que a rede AGIVEST apresenta as seguintes características: (1) é formada essencialmente por pequenas empresas, com número médio aproximado de seis funcionários; (2) as empresas situam-se geograficamente próximas, abrangendo um raio de $180 \mathrm{~km}$; (3) as empresas operam no segmento de confecções; (4) a rede é autogerenciada por seus membros por meio de estrutura de coordenação, formada por um presidente e vice-presidente, supervisionados pelo conselho de administração, conselho de ética e conselho fiscal; (5) as decisões estratégicas da rede são deliberadas por meio de assembléia geral; (6) as questões controversas podem ser resolvidas por meio da aplicação de alguns instrumentos legais - estatuto da rede, código de ética e regimento interno - que permitem melhor estrutura de governança da rede; e (7) as empresas da rede trabalham com duas marcas - a marca AGIVEST para os produtos comercializados por meio da rede e uma marca particular de cada empresa para os produtos comercializados individualmente pelas empresas.

Segundo essas características e as orientações de Perrow (1992), Human e Provan (1997) e Marcon e Moinet (2000), a AGIVEST pode ser classificada como uma rede horizontal de cooperação. Diferentemente de outras tipologias de redes de PMEs, como as redes verticais de subcontratação, as redes horizontais de cooperação são formadas por PMEs, com a finalidade de trabalhar de forma coletiva para alcançar certos objetivos estratégicos que dificilmente alcançariam de forma individualizada. A horizontalidade é decorrência dos seguintes fatores: (1) a rede é formada somente por pequenas e médias empresas; (2) as decisões são tomadas em processo participativo, em que cada empresário utiliza o seu poder de voto para as escolhas estratégicas da rede; e (3) a simetria de poder econômico e político entre as PMEs associadas está presente.

Mesmo sendo constituída há apenas um ano, ou seja, ainda está em fase de organização e formação, a análise das entrevistas possibilitou identificar alguns benefícios estratégicos da rede para o desenvolvimento e desempenho das PMEs associadas. No Quadro 2, são apresentados alguns desses benefícios, a partir das evidências empíricas observadas. 


\section{Quadro 2: Benefícios Estratégicos e Evidências Empíricas da Pesquisa}

\begin{tabular}{|c|c|}
\hline $\begin{array}{c}\text { Benefícios das } \\
\text { redes }\end{array}$ & Evidências empíricas da pesquisa \\
\hline $\begin{array}{l}\text { Aprendizagem } \\
\text { coletiva }\end{array}$ & $\begin{array}{l}\text { "São feitas visitas às indústrias da rede, e cada empresário mostra o seu sistema de } \\
\text { produção, o sistema de compra de mercadorias, o sistema de vendas e, a partir daí, } \\
\text { começamos a analisar o que pode ser melhorado nas nossas empresas [...], cada um } \\
\text { transmite as experiências que tem aos demais colegas. Ninguém esconde de quem } \\
\text { compra, o que produz, a maneira de produção" (Dirigente de PMEs). } \\
\text { "A partir do momento em que eu entrei na rede, comecei a ver quanto era pequeno } \\
\text { o meu negócio [...]; eu não tinha controle de custo, não sabia administrar e não sei } \\
\text { como minha empresa sobrevivia. A partir do momento em que comecei a } \\
\text { participar de cursos e a conversar com os demais colegas, descobri que os } \\
\text { problemas são muito semelhantes e as soluções podem ser encontradas pelo } \\
\text { conjunto" (Dirigente de PMEs). }\end{array}$ \\
\hline $\begin{array}{l}\text { Economias de } \\
\text { escala }\end{array}$ & $\begin{array}{l}\text { "Quando trabalhávamos sozinhos, caso um bom cliente fizesse um pedido de dez } \\
\text { mil peças, eu não conseguiria atender; porém agora é possível atender, pois todas } \\
\text { as indústrias vão fazer uma parte do pedido" (Dirigente de PMEs). } \\
\text { "Realização em conjunto de propaganda e publicidade dos produtos e da marca } \\
\text { AGIVEST" (Presidente da rede). } \\
\text { "Contrato de uma assessoria para toda a rede AGIVEST para a garantia de } \\
\text { fornecimento de crédito aos clientes, sendo que esse benefício já era utilizado } \\
\text { pelas grandes empresas e, por meio da rede, o benefício de segurança de crédito } \\
\text { nas vendas acabou chegando também às PMEs" (Dirigente de PMEs). }\end{array}$ \\
\hline $\begin{array}{l}\text { Economias de } \\
\text { escopo e de } \\
\text { especialização }\end{array}$ & $\begin{array}{l}\text { "Na elaboração de um catálogo [coleção de produtos] para a Fenit [Feira Nacional } \\
\text { da Indústria Têxtil], cada empresa produziu modelos específicos; porém, ao } \\
\text { considerar o número de } 44 \text { empresas, obteve-se um considerável grau de } \\
\text { diversificação da coleção" (Consultora da rede). }\end{array}$ \\
\hline $\begin{array}{l}\text { Poder de } \\
\text { barganha }\end{array}$ & $\begin{array}{l}\text { "Muitas empresas compravam de atacados e hoje compram diretamente das } \\
\text { fábricas e ganham em torno de } 25 \% \text { de redução no custo das compras" (Presidente } \\
\text { da rede). } \\
\text { "A rede consegue fazer um lobbying junto aos governos municipal e estadual para } \\
\text { obter incentivos" (Consultora da rede). }\end{array}$ \\
\hline $\begin{array}{l}\text { Ampliação de } \\
\text { mercado }\end{array}$ & $\begin{array}{l}\text { "Todos os anos, íamos às feiras para comprar e esse ano ano nós fomos à Fenit } \\
\text { [Feira Nacional da Indústria Têxtil] para vender nossos produtos" (Dirigente de } \\
\text { PMEs). } \\
\text { "Muitas empresas da rede nem imaginavam como poderiam ter um representante; } \\
\text { porém, com a troca de informações com outras empresas da rede, tiveram o } \\
\text { conhecimento de possíveis representantes e a orientação da maneira como } \\
\text { deveriam proceder" (Consultora da rede). }\end{array}$ \\
\hline $\begin{array}{l}\text { Redução dos } \\
\text { custos de } \\
\text { transação }\end{array}$ & $\begin{array}{l}\text { "Existe a troca de insumos, máquinas e mercadorias entre as empresas da rede, } \\
\text { processo facilitado pela confiança estabelecida entre os empresários da rede" } \\
\text { (Dirigente de PMEs). }\end{array}$ \\
\hline $\begin{array}{l}\text { Facilitação do } \\
\text { processo de } \\
\text { inovação }\end{array}$ & $\begin{array}{l}\text { "Após ter entrado na rede, minha empresa melhorou a metodologia de produção } \\
\text { [...]. Com uma consultoria contratada por meio da rede, mudamos todo o sistema } \\
\text { de produção [...]; somente em mudar alguns processos, aumentamos } 40 \% \text { a } \\
\text { produção, sem aumentar pessoal ou máquinas" (Dirigente de PMEs). }\end{array}$ \\
\hline
\end{tabular}

Uma das respostas unânimes obtidas na pesquisa foi a de que o maior ganho por meio da formação da rede consistiu no compartilhamento de informações e de conhecimentos entre as empresas participantes. As informações compartilhadas que mais trouxeram benefícios para a rede versam sobre processos de produção, fornecedores, insumos, tecnologias e mercado. Tais informações foram 
compartilhadas em intensa inter-relação social que ocorre de maneira formal e informal entre os empresários da rede. $\mathrm{O}$ ambiente de interação proporciona um processo de coevolução para as empresas, isto é, conforme Nonaka, Toyama e Konno (2001) cada empresa evolui a partir do conhecimento e das experiências de outras.

A aprendizagem coletiva ocorre na rede tanto pela interação das empresas quanto pela participação em cursos, palestras e serviços de consultoria. Outro exemplo que demonstra novas possibilidades de aprendizagem para os empresários da rede foi a realização de 120 horas de curso de formação gerencial, proporcionado pelo governo do Estado e apresentado com o objetivo de desenvolver os conceitos de gestão junto aos empresários. Segundo Marcon e Moinet (2000), observa-se que o aprendizado entre as empresas da rede é potenciado pelo ambiente de forte interação entre os empresários participantes.

Ao participar como observador em uma assembléia da rede, que apresentava como objetivo deliberar sobre algumas decisões estratégicas, como, por exemplo, a participação ou não da rede em uma ferira estadual, o pesquisador pôde perceber que a decisão foi tomada em meio a um intenso processo de aprendizado, em que várias alternativas e sugestões eram apreciadas em clima tenso, porém construtivo. Além disso, as decisões ocorrem em processo de discussões, frustrações, questionamentos e dúvidas; mas no final persiste a sensação de que as decisões mais satisfatórias foram tomadas. Esse ambiente participativo no processo decisório permite uma coordenação transparente dos interesses de cada um dos atores que fazem parte da rede. Essa transparência permite maior confiança que, segundo Jarillo (1988), é fundamental para a existência de cooperação.

Seguindo a análise, observa-se freqüentemente que as PMEs, no momento de competir em mercados maiores, encontram problemas de baixo volume de produção. No caso da rede AGIVEST, esse problema foi atenuado consideravelmente, pois a sua capacidade de produção foi multiplicada pela capacidade de cada empresa associada. Assim, contrariando alguns princípios econômicos de produção, a rede AGIVEST consegue economias de escala, pelo volume de produção; economias de especialização, pelo fato de cada empresa especializar-se na produção de algumas peças que farão parte da coleção ou pedido do cliente; e economias de escopo, pelo portfólio diversificado na produção da rede. A partir desses efeitos de produção, a rede consegue vantagens de custo e de diferenciação, estratégia que dificilmente poderia ser alcançada por uma PME que trabalhasse de forma individual.

Já alguns dos benefícios que até então eram somente privilégios de grandes empresas, como os serviços especializados de garantia de crédito nas vendas, foram estendidos também às PMEs. Nesse sentido, viabilizou-se a assinatura de 
contrato entre a rede AGIVEST e uma consultoria de crédito para a prestação de serviços a todas as PMEs da rede. Esse exemplo demonstra que as empresas tiveram acesso a recursos não-disponíveis anteriormente à formação da rede, indo ao encontro das evidências teóricas apresentadas por Human e Provan (1997).

A barganha junto a fornecedores apresentou bons resultados para a rede. Por comprar insumos diretamente de fábrica (por exemplo, a compra de tecido em volumes maiores), as empresas têm alcançado em média uma redução de $25 \%$ do preço em relação às aquisições em pequenos lotes de forma individual. O acesso a novos representantes também foi facilitado pela rede, sobretudo pela troca de informações entre as empresas.

Chamou a atenção a manifestação de uma empresária sobre os resultados da participação em uma feira nacional. Para tal empresária, o que restava para as PMEs era participar em feiras somente como compradores e o fato de estarem organizadas em rede possibilitou irem às feiras para vender seus próprios produtos. Tal participação conta com incentivos públicos, obtidos em parte por meio de lobbying junto aos governos. Outros benefícios observados foram as transações entre as empresas de produtos físicos: matérias primas, produtos prontos, máquinas e demais insumos. Certamente, essas transações ocorrem com menor custo em relação às transações realizadas diretamente no mercado. Atividades de marketing conjunto também podem ser observadas, bem como o aumento da confiança e do otimismo que a formação da rede proporcionou aos empresários participantes.

Quanto ao processo de inovação, observou-se que algumas melhorias incrementais foram realizadas, em especial nos processos de produção. Um empresário exemplificou que, a partir de algumas simples modificações no sistema de produção e orientado por uma consultoria, aumentou em $40 \%$ a produção, sem qualquer investimento adicional em máquinas ou mão-de-obra. Esse processo de melhoria dos processos, mesmo não sendo considerado uma inovação radical, demonstra que a partilha de informações e conhecimentos no âmbito de uma rede poderá facilitar a reunião de complementaridade de habilidades de diferentes firmas, conforme evidenciado por Richardson (1972). A busca de assessoria de um reconhecido estilista de moda da região para desenhar a coleção de produtos a serem comercializados na Fenit 2002, foi outro exemplo de como as PMEs poderão ter acesso a conhecimentos externos, fundamentais para os processos de inovação, conforme evidenciado por Powell, Koput e Smith-Doerr (1996).

A rede AGIVEST conta ainda com ambiente de densas relações institucionais, comprometidas com o desenvolvimento das PMEs e da região. Assim, os governos 
municipais, prefeituras dos municípios em que as PMEs estão localizadas, os governos estaduais, por meio da SEDAI, as universidades, como a Universidade de Ijuí (UNIJUÍ), e as instituições de apoio às PMEs, como o Serviço Brasileiro de Apoio às Micro e Pequenas Empresas (SEBRAE), oferecem forte apoio ao desenvolvimento da rede.

\section{Considerações Finais}

O presente trabalho compilou diferentes reflexões teóricas sobre o potencial de contribuição da configuração em rede como recurso que os gestores poderão utilizar para obter vantagens competitivas. Buscou-se apresentar algumas evidências empíricas de uma pesquisa que está sendo conduzida na rede AGIVEST. Os resultados demonstram forte otimismo por parte dos empresários sobre os benefícios que a rede já produziu e, sobretudo, pela expectativa com os resultados futuros que as PMEs poderão alcançar.

Entre os impactos observados pela formação da rede para as PMEs, destacamse os econômicos, os comportamentais e os de aprendizagem. Os impactos econômicos são decorrentes de atividades como a participação e comercialização de produtos em feiras, a melhoria de processos produtivos, a barganha de preços junto a clientes, o acesso a novos representantes, a garantia de fornecimento de crédito, a comercialização de produtos entre as empresas e a obtenção de economias de escala, escopo e especialização. Já o impacto na aprendizagem pode ser resultado de forte interação das empresas e do acesso a cursos e palestras de desenvolvimento empresarial. Por último, o impacto no comportamento é observado pela existência de espírito coletivo entre os empresários, fundamental para a existência de cooperação.

Desse modo, embora os resultados empíricos deste artigo apresentem algumas limitações de verticalidade e extensão, uma vez que dizem respeito a um estudo exploratório na rede AGIVEST, suas evidências empíricas reforçam a tese central da pesquisa: a de que as PMEs poderão utilizar a configuração em rede horizontal de cooperação como recurso estratégico de competitividade. No entanto, para uma sólida comprovação dessa tese, os autores estão aprofundando suas pesquisas, tanto no contexto da rede AGIVEST, quanto em outros contextos de redes de PMEs no Brasil e no exterior, mais especificamente na França, onde um dos autores está desenvolvendo parte da pesquisa.

Para finalizar, deve-se destacar que o tema redes interorganizacionais está despertando crescente interesse de acadêmicos, empresários e governantes, 
sobretudo pela possibilidade de sustentar o desenvolvimento e a competitividade de PMEs e regiões. Nesse sentido, abre-se um leque de necessidades e oportunidades de pesquisas e estudos com o objetivo de permitir melhor compreesão da estrutura e do desempenho das redes horizontias de PMEs.

Artigo recebido em 22.07.2003. Aprovado em 12.12.2003.

\section{REFERÊNCIAS BIBLIOGRÁFICAS}

\section{AMATO NETO, J.}

Redes de cooperação produtiva e clusters regionais: oportunidades para as pequenas e médias empresas. São Paulo: Atlas, 2000.

BOSS, R. W.

Trust and managerial problem solving revisited.

Group and

Organizational Studies, p. 331-342, Sept. 1978.

BRUSCO, S.;

RIGHI, E.

Local government, industrial policy and social consensus: the case of Modena (Italy). Economy and Society, v. 18, p. 405-424, 1989.

\section{BURT, R. S.}

Structural holes. Cambridge, MA: Harvard University Press, 1992.

CAGLIO, A.

Networks and information technology: competing through extranets. In: COMMUNITY OF EUROPEAN MANAGEMENT SCHOOLS, 3., Louvain-la-Neuve, 1998. Proceedings... [S.l.: s.n.], 1998.
CASAROTTO FILHO, N.;

PIRES, L. H.

Redes de pequenas e médias empresas e desenvolvimento local. São Paulo: Atlas, 1999.

CASTELLS, M.

A era da informação: economia, sociedade e cultura - a sociedade em rede. São Paulo: Paz e Terra, 1999.

COASE, R. H.

The nature of the firm. Economica, v. 4, p. 386-405, 1937.

DIMAGGIO, P.;

POWELL, W.

The iron cage revisited: institutional isomorphism and collective rationality in organizational fields. American Sociological Review, v. 48, p.147-160, 1983.

EBERS, M.

The formation of interorganizational networks. New York: Oxford University Press, 1997. 
EBERS, M.;

JARILLO, J. C.

The construction, forms, and consequences of industry networks.

International Studies of Management and Organization, v. 27, p. 3-21, Winter 1998.

ECCLES, R. J.

The quasi firm in the construction industry. Journal of Economic Behavior and Organizations, v. 2, p. 335-357, 1981.

FAYARD, P.

O jogo da interação: informação e comunicação em estratégia. Caxias do Sul: EDUCS, 2000.

FOMBRUN, C. J.

Strategies for network research in organizations. Academy of Management Review, v. 7, p. 280291, 1997.

GRABHER, G.

The embedded firm: the socioeconomics of industrial networks. London: Routledge, 1993.

GRANDORI, A.;

SODA, G.

Inter-firm networks: antecedents, mechanisms and forms.

Organization Studies, v. 16, n. 2, 1995.

HENDERSON, B. D.

As origens da estratégia. In: MONTGOMERY, C. A.; PORTER, M. Estratégia: a busca das vantagens competitivas. Rio de Janeiro: Campus, 1998.
HUMAN, S. E.;

PROVAN, K. G.

An emergent theory of structure and outcomes in small-firm strategic manufacturing network. Academy of Management Journal, v. 40, n. 2, p. 368-403, 1997.

INZERILLI, G.

The Italian alternative: flexible organization and social management.

International Studies of Management and Organization, v. 20, p. 6-21, 1990.

JARRILLO, J. C.

On strategic networks. Strategic Management Journal, v. 9, p. 31-41, 1988.

KNORRINGA, P.;

MEYER-STAMER, J.

New dimensions in local enterprise co-operation and development: from clusters to industrial districts. In: Clusters e sistemas locais de inovação. Campinas: UNICAMP, 1999.

LORENZONI, G.;

ORNATI, O.

Constellations of firms and new ventures. Journal of Business Venturing, v. 3, p. 41-57, 1988.

MARCON, M.;

MOINET, N.

La stratégie-réseau. Paris: Éditions Zéro Heure, 2000.

MILES, R. E.;

SNOW, C. C.

Fit, failure and the hall of fame. California Management Review, p. 10-28, 1984. 
MOWERY, D. C.;

ROSENBERG, $\mathrm{N}$.

Technology and the pursuit of economic growth. Cambridge, MA: Cambridge University Press, 1989.

NAPOLEONI, C.

Il pensiero economico del 900 . Turim: Giulio Einaudi Editore, 1963.

NOHRIA, N.;

ECCLES, R.

Networks and organizations: structure, form and action. Boston: Harvard Business School Press, 1992.

NONAKA, I.;

TOYAMA, R.;

KONNO, N.

SECI, ba and leadership: a unified model of dynamic knowledge creation. In: NONAKA, I.; TEECE, D. J. Managing industrial knowledge: creation, transfer and utilization. London: Sage Publications, 2001.

OLIVER, C.

Determinants of inter-organizational relationships: integration and future directions. Academy of Management Review, v. 15, n. 2, p. 241-265, 1990.

OLIVER, A. L.;

EBERS, $M$.

Networking network studies: an analysis of conceptual configurations in the study of inter-organizational relationships. Organization Studies, v. 19, p. 549-583, 1998.
PERROW, C.

Small-firm networks. In: NOHRIA, N.; ECCLES, R. Networks and organizations: structure, form and action. Boston: Harvard Business School Press, 1992.

PERUCCI, R.;

POTTER, H. R.

Networks of power. Berlin: De Gruyter, 1989.

PFEFFER, J.;

SALANCIK, G.R.

The external control of organizations: a resource dependence perspective. New York: Harper and Row, 1978.

POWELL, W. W.

Hybrid organizational arrangements: new form or transitional development? California Management Review, p. 67-87, 1987.

Learning from collaboration: knowledge and networks in the biotechnology and pharmaceutical industries. California Management Review, v. 40, p. 228-240, Spring 1998.

POWELL, W. W.;

KOPUT, K. W.;

SMITH-DOERR, L.

Inter-organizational collaboration and the locus of innovation: networks of learning in biotechnology. Administrative Science Quarterly, v. 41, n. 1, p. 116-145, 1996.

RICHARDSON, G. B.

The organization of industry. Economic Journal, p. 883-896, 1972. 
ROGERS, E. M.;

KINCAID, D. L.

Communication networks: toward a new paradigm for research. New York: Free Press, 1981.

ROTHWELL, R.

Industrial innovation: success, strategy, trends. In: DODGSON, M.; ROTHWELL, R. The handbook of industrial innovation. Cheltenham: Edward Elgar, 1995.

\section{SABEL, C.}

Moebius-strip organizations and open labor markets: some consequences of the reintegration of conception and execution in a volatile economy. In: COLEMAN, J.; BOURDIEU, P. Social theory for a changing society. Boulder: Westview Press, 1991.

SALANCIK, G. R.

A good network theory of organization. Administrative Science Quarterly, v. 40, p. 345-349, 1995.
SAXENIAN, A.

Regional advantage: culture and competition in Silicon Valley and Route 128. Cambridge, MA: Harvard University Press, 1994.

SOUZA, M. C. A. F. DE.

Pequenas e médias empresas na reestruturação industrial. Brasília: Sebrae, 1995.

TEECE, D. J.

Economies of scope and the scope of enterprise. Journal of Economic Behavior and Organization, v. 1, p. 223-247, 1980.

TURATI, C.

Economia ed organizzazione delle joint venture. Milan: EGEA, 1990.

WILLIAMSON, O. E.

Transaction-cost economics: the governance of contractual relations. Journal of Law and Economics, v. 22, p. 223-261, 1979. 